\title{
Age and Growth of the Labrid Fish Halichoeres poecilopterus in Ago Bay, Central Japan*1
}

\author{
Seishi Kimura, ${ }^{* 2}$ Yoshinori Nakayama, ${ }^{* 3}$ and Koichiro Mori ${ }^{* 3}$ \\ (Received June 10, 1991)
}

\begin{abstract}
The present report deals with the age and growth of the wrasse Halichoeres poecilopterus (Pisces: Labridae) in relation to sex types (primary male, female, and secondary male) examined by scale reading, based on fish taken from Ago Bay, Mie Prefecture, Japan from July 1977 to August 1985.

The scale removed from the ventrolateral portion of the trunk was the most suitable for age determination, and the ring marks on it were clearly distinguishable. Examination of marginal increments of scale showed that the ring marks formed once a year from January to March. The relationship between standard length $(S L, \mathrm{~mm})$ and body weight $(W, \mathrm{~g})$ was expressed by the formula: $\log _{10} W=3.15 \log _{10} S L-5.00$. There were no significant differences in the mean backcalculated lengths at the time of each ring formation between primary males and hermaphroditic individuals (females and secondary males). The growth curves for length and weight were described as follows: $L_{t}=211(1-\exp (-0.224(t+1.049))) ; W_{t}=210(1-\exp (-0.224(t+1.049)))^{3.15}$; where $L_{t}=$ standard length at age $t ; W_{t}=$ body weight at age $t$. The sex change from females to secondary males in hermaphroditic individuals took place mostly at age 4 or older. The larger females have a stronger tendency to change to secondary males in a certain age group.
\end{abstract}

The wrasse Halichoeres poecilopterus is a very common labrid fish distributed widely in the inshore waters from southern Hokkaido to Kyushu in Japan. This species is widely used as a game fish and for commercial food especially in western Japan.

The polychromatism and/or sex change in this fish has been extensively studied,,$^{1-8}$ because it is a representative protogynous hermaphroditic fish in Japan. However, there are a few reports on the fishery biology of the fish. Yamaguchi*4 has noted the feeding habits. Recently, Hashimoto et al. ${ }^{\text {i) }}$ reported the age and growth of the fish from the Seto Inland Sea, western Japan, but they did not discuss the relationship between age and sex change nor between growth and sex.

The objective of our study was to increase the knowledge of the fishery biology of labrid fishes. In the present paper, the age and growth of $H$. poecilopterus in relation to sex types was discussed by analyzing the ring marks on the scales.

\section{Materials and Methods}

The materials used in this study were caught with angling gear, gill nets, set nets, and a small beam trawl in Ago Bay, Mie Prefecture, Japan (lat. $34^{\circ} 16-17^{\prime} \mathrm{N}$, long. $136^{\circ} 46-48^{\prime} \mathrm{E}$ ) during the period from July 1977 to August 1985. No fish were sampled between January and March because the fish hibernates in the sand on the seabed. ${ }^{103}$ The specimens were preserved in $10 \%$ buffered formalin. A total of 711 specimens were measured (total length $(T L)$ and standard length $(S L)$ to the nearest millimeter) and weighed (body weight $(W)$ to the nearest 0.1 or 0.01 gram). These specimens ranged from 7 to $203 \mathrm{~mm} S L$ and from 0.01 to $190.6 \mathrm{~g} W$.

For comparison of the scales on various body portions, five scales on each different portion (Fig. 1) were removed from 50 specimens of 99 $173 \mathrm{~mm} S L$. The scales on portion $\mathrm{D}$ taken from 629 specimens of $18-203 \mathrm{~mm} S L$ were used

* Fishery Biology of Labrid Fishes-I.

*2 Fisheries Research Laboratory, Mie University, P. O. Box 11, Wagu, Shima, Mie 517-07, Japan (朴杪志:

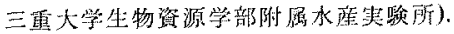

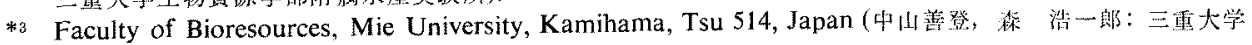
生物資源学部).

* Y. Yamaguchi: Shôwa 53 Nendo Gyogyô Shigen Kenkyû Kaigi, Nishinihon Sokouo Bukai Kaigi Hôkoku, 51-57 (1979). 


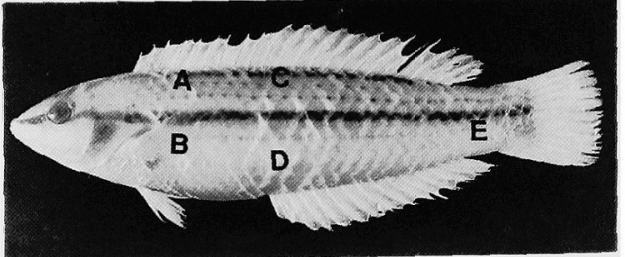

Fig. 1. Photograph of Halichoeres poecilopterus showing the body portions (A-E) from which scales were removed.

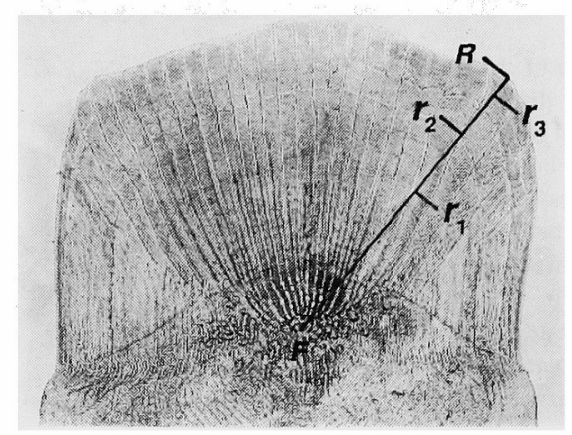

Fig. 2. Scale of Halichoeres poecilopterus $(117 \mathrm{~mm}$ $S L$ ) showing area of measurement. $F$, focus; $R$, scale radius; $r_{1}-r_{3}$, the first to the third ring radii.

for age determination and growth analyses. The scales were soaked in $10 \%$ potassium hydroxide for several minutes, washed with water and dehydrated with alcohol, mounted between two glass slides, and viewed at $\times 20$ magnification with a projector. Measurements were made in the embedded part along a line from the focus to the anterolateral angle of the scale. Distances from the focus to each ring mark and to the margin were recorded (Fig. 2).

The gonads of 515 specimens $(45-203 \mathrm{~mm} S L)$ were examined histologically. The sexes of these specimens were assigned to the following types: primary males (126 specimens, $89-179 \mathrm{~mm} S L$ ) $=$ individuals possessing the primary testes $;^{7,11}$ ) females (215 specimens, 45-184 $\mathrm{mm} S L$ ) =individuals possessing the ovaries without any testicualr tissue; secondary males (174 specimens, 118-203 $\mathrm{mm} S L$ ) =individuals possessing the hermaphroditic gonads or secondary testes. ${ }^{7,11}$ Females and secondary males were collectively regarded as hermaphroditic individuals because the secondary male originates from the female. Most of the small specimens (196 individuals, 7-54 $\mathrm{mm} S L$ ) were not sexed.

\section{Results}

Scale Morphology

The scales of this species were cycloid with clear circuli or ridges on their embedded part. The ring marks on the scale were definable as the narrow zones of closely spaced and irregularly arranged circuli (Fig. 2). Circuli which cut across other circuli ("cutting over") were also observed in the zone. There were no marks nor

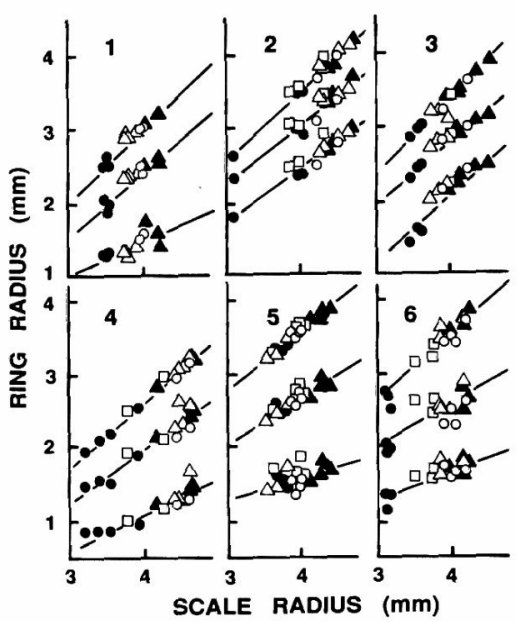

Fig. 3. Relationships between scale radius and ring radii on the scales removed from five body portions, A $(\bigcirc), \mathrm{B}(\bullet), \mathrm{C}(\triangle), \mathrm{D}(\mathbf{\Delta})$, and $\mathrm{E}(\square)$ in six specimens. 1, $114 \mathrm{~mm} S L ; 2,144 \mathrm{~mm} ; 3$, $118 \mathrm{~mm}$; $118 \mathrm{~mm} ; 5,140 \mathrm{~mm}$; 6, $132 \mathrm{~mm}$.

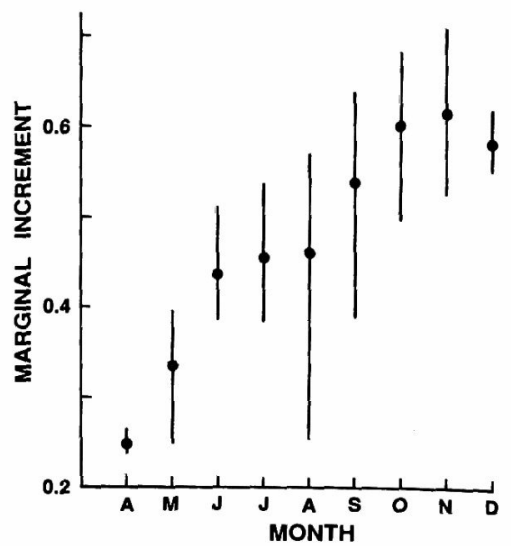

Fig. 4. Monthly change in the marginal increment of scale $\left(\left(R-r_{n}\right) /\left(r_{n}-r_{n-1}\right)\right.$; where $R=$ scale radius, $r_{n}=$ the $n$-th ring radius). Circles indicate mean values and vertical lines the ranges. 
Table 1. Number of specimens in each ring group

\begin{tabular}{|c|c|c|c|c|c|}
\hline \multirow{2}{*}{$\begin{array}{l}\text { Ring } \\
\text { group }\end{array}$} & \multirow{2}{*}{ Primary males } & \multicolumn{2}{|c|}{ Hermaphroditic individuals } & \multirow{2}{*}{ Sex unknown } & \multirow{2}{*}{ Total } \\
\hline & & Females & Secondary males & & \\
\hline 0 & 0 & 0 & 0 & $\begin{array}{r}114(34 \mathrm{~mm}, \\
100 \%)\end{array}$ & $\begin{array}{r}114(34 \mathrm{~mm}, \\
100 \%)\end{array}$ \\
\hline 1 & 0 & $16(68 \mathrm{~mm}$, & 0 & $\begin{array}{l}3(46 \mathrm{~mm}, \\
15.8 \%)\end{array}$ & $\begin{array}{r}19(64 \mathrm{~mm}, \\
100 \%)\end{array}$ \\
\hline 2 & $\begin{array}{c}4(105 \mathrm{~mm}, \\
17.4 \%)\end{array}$ & $\begin{array}{c}18(100 \mathrm{~mm}, \\
78.3 \%)\end{array}$ & $\begin{array}{c}1(118 \mathrm{~mm}, \\
4.3 \%)\end{array}$ & 0 & $\begin{array}{r}23(102 \mathrm{~mm}, \\
100 \%)\end{array}$ \\
\hline 3 & $\begin{array}{c}17(117 \mathrm{~mm}, \\
23.6 \%)\end{array}$ & $\begin{array}{r}53(115 \mathrm{~mm} \\
73.6 \%)\end{array}$ & $\begin{array}{c}2(129 \mathrm{~mm}, \\
2.7 \%)\end{array}$ & 0 & $\begin{array}{r}72(116 \mathrm{~mm}, \\
100 \%)\end{array}$ \\
\hline 4 & $\begin{array}{l}32(132 \mathrm{~mm}, \\
21.1 \%)\end{array}$ & $\begin{array}{r}74(131 \mathrm{~mm}, \\
48.6 \%)\end{array}$ & $\begin{array}{c}46(149 \mathrm{~mm}, \\
30.2 \%)\end{array}$ & 0 & $\begin{array}{r}152(136 \mathrm{~mm}, \\
100 \%)\end{array}$ \\
\hline 5 & $\begin{array}{l}56(150 \mathrm{~mm}, \\
32.0 \%)\end{array}$ & $\begin{array}{r}42(144 \mathrm{~mm}, \\
24.0 \%)\end{array}$ & $\begin{array}{c}77(158 \mathrm{~mm}, \\
44.0 \%)\end{array}$ & 0 & $\begin{array}{r}175(152 \mathrm{~mm} . \\
100 \%)\end{array}$ \\
\hline 6 & $\begin{array}{c}15(164 \mathrm{~mm}, \\
23.4 \%)\end{array}$ & $\begin{array}{c}12(158 \mathrm{~mm} \\
18.8 \%)\end{array}$ & $\begin{array}{c}37(171 \mathrm{~mm}, \\
57.8 \%)\end{array}$ & 0 & $\begin{array}{r}64(167 \mathrm{~mm}, \\
100 \%)\end{array}$ \\
\hline 7 & $\begin{array}{c}1(179 \mathrm{~mm}, \\
10.0 \%)\end{array}$ & 0 & $\begin{array}{c}9(187 \mathrm{~mm}, \\
90.0 \%)\end{array}$ & 0 & $\begin{array}{r}10(186 \mathrm{~mm}, \\
100 \%)\end{array}$ \\
\hline
\end{tabular}

Remarks: The mean observed standard length and percentage occurrence of each sex are shown in parentheses.

signs indicating the sex change on the scales removed from secondary males.

\section{Comparison of the Scales Taken from Various} Body Portions

The scales removed from portions $\mathbf{A}$ and $\mathbf{D}$ were dorsoventrally symmetrical in shape, but those from $\mathbf{B}, \mathbf{C}$, and $\mathbf{E}$ were asymmetrical.

The relationship between scale radius and ring radii ("similarity") was examined on the scales removed from five body portions, based on six specimens of $114-144 \mathrm{~mm} S L$ possessing three ring marks on each scale. This relationship was expressed by three regression lines in each specimen (Fig. 3), and a strong correlation between them was well recognized $(r=0.797$ to 0.979 ; $r=$ correlation coefficient). Thus, the ring marks on the scales taken from any portion of the body were formed similarly and the ring radii varied with scale size.

The correlation between standard length and scale radius and the frequency of regenerated scale were inspected for the scales taken from five body portions, based on 50 specimens. The correlation coefficients were calculated to be 0.928 , $0.820,0.923,0.931$, and 0.813 in the scales removed from portions $A$ to $E$, respectively. There was a significant difference between those coefficients at $1 \%$ level, and the correlations in $\mathbf{A}, \mathbf{C}$, and $\mathbf{D}$ were stronger than those in $\mathbf{B}$ and $\mathbf{E}$. Regenerated scales appeared at the rates of $32.0 \%, 22.4 \%$,
$36.8 \%, 22.8 \%$, and $35.2 \%$ in the scales taken from portions $\mathbf{A}$ to $\mathbf{E}$, respectively. The rates in $\mathbf{B}$ and $\mathbf{D}$ were significantly lower than those in $\mathbf{A}, \mathbf{C}$, and $\mathbf{E}$ at $1 \%$ level. Average size of the scales became smaller in the order, $\mathbf{D}, \mathbf{A}, \mathbf{C}, \mathbf{B}$, and $\mathrm{E}$.

From the above results, the scales taken from portion $\mathbf{D}$ were the most suitable for age determination because of the strong correlation between standard length and scale radius, low occurrence of regenerated scale, symmetry in shape, and large scale size.

\section{Period of Ring Formation}

The marginal increment of the scale $\left(\left(R-r_{n}\right) /\right.$ $\left(r_{n}-r_{n-1}\right)$; where $R=$ scale radius in $\mathrm{mm}, r_{n}=$ the

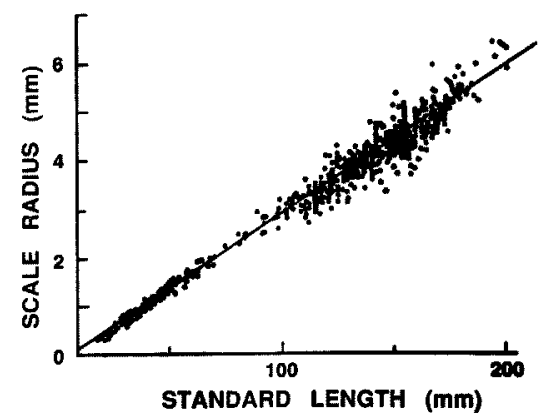

Fig. 5. Relationship between scale radius and standard length. 
Table 2. Mean back-calculated standard lengths $(\mathrm{mm})$ at the time of each ring formation

\begin{tabular}{llllllll}
\hline \hline & $l_{1}$ & $l_{2}$ & $l_{3}$ & $l_{4}$ & $l_{5}$ & $l_{0}$ & $l_{7}$ \\
\hline Primary male & 61 & 92 & 114 & 131 & 145 & 158 & 175 \\
Hermaphroditic individual & 61 & 92 & 115 & 133 & 149 & 164 & 181 \\
\hline Female & 59 & 89 & 110 & 126 & 139 & 153 & 181 \\
Secondary male & 63 & 96 & 121 & 139 & 153 & 166 & 181 \\
\hline Whole & 61 & 92 & 115 & 133 & 148 & 162 & 180 \\
\hline
\end{tabular}

$n$-th ring radius in $\mathrm{mm}$ ) was examined to estimate the period of ring formation, based on 485 specimens possessing 1-6 ring marks. The monthly change in the marginal increment is shown in Fig. 4. The maximum values were displayed between October and December and the minimum value appeared in April. These data indicated that the ring marks on scales were formed once a year during the period from January to March. The ring marks could therefore be regarded as the annual rings.

No ring marks were observed on the scales taken from young fish sampled in December (34$54 \mathrm{~mm} S L$ ), but the specimen of similar size in April ( $48 \mathrm{~mm} S L$ ) had a single ring on the scale. This observation suggested that the first ring was also formed between January and March. The spawning of this species took place from July to September in this area.* The first ring was, therefore, formed about a half year after hatching.

\section{Age Composition and Observed Length}

A result of age determination is shown in Table 1. The specimens possessing 7 rings were the eldest in both primary males and hermaphroditic individuals. In the latter, the secondary male first appeared in 2-ring group, but were very few in 2- and 3-ring groups. They increased in percentage occurrence rapidly in the 4-ring group, then gradually increased in the 5- to 7-ring groups. In contrast, the females decreased in percentage occurrence with age, and they were absent in the 7-ring group. Therefore, it can be considered that the sex change took place mostly at age 4 or elder. The absence of the primary males in the 1-ring group is most likely attributable to only failure in collection of the materials.

There were no significant differences in the mean observed lengths in 2- to 6-ring groups between primary males and hermaphroditic individuals at $1 \%$ level. In hermaphroditic individuals of 4- to 6-ring groups, the mean lengths of secondary males were significantly lager than those of females at the $1 \%$ level.

\section{$S L-T L$ and SL-W Relationships}

The were no significant differences in the $S L-T L$ and $S L-W$ relationships between sexes at the $5 \%$ level. These relationships were expressed by the following equations.

$$
\begin{aligned}
& \log _{10} T L=0.989 \log _{10} S L+0.102(r=0.999) \\
& \log _{10} W=3.15 \log _{10} S L-5.00(r=0.997)
\end{aligned}
$$

\section{R-SL Relationship and Back-Calculated Length}

There was no significant difference in the $R-S L$ relationship between sexes at the $5 \%$ level. The relationship of 629 specimens was represented by the following equation (Fig. 5).

$$
R=0.030 S L-0.155(r=0.985)
$$

Figure 5 shows the variation of scale radius in specimens of the same length. The ring radii also varied with the scale radius as mentioned above. Consequently the ring radii could alter with each specimen. In order to remove the variation of ring radii, each ring radius was standardized by the following equation. ${ }^{12}$

$$
\hat{r}_{n}=(\hat{R} / R) r_{n}
$$

Where $\hat{R}=$ standard scale radius computed from standard length by applying the equation (3); $R=$ measured scale radius; $\hat{r}_{n}=$ standard ring radius; $r_{n}=$ measured ring radius.

The standard length at the time of ring formation was back-calculated from each standard ring radius by applying equation (3). The mean back-calculated lengths for primary males and hermaphroditic individuals are shown in Table 2 . The differences in the mean lengths at the time of each ring formation between primary males and hermaphroditic individuals were not significant at the $1 \%$ level.

\footnotetext{
* S. Kimura and T. Kiriyama, unpublished data.
} 


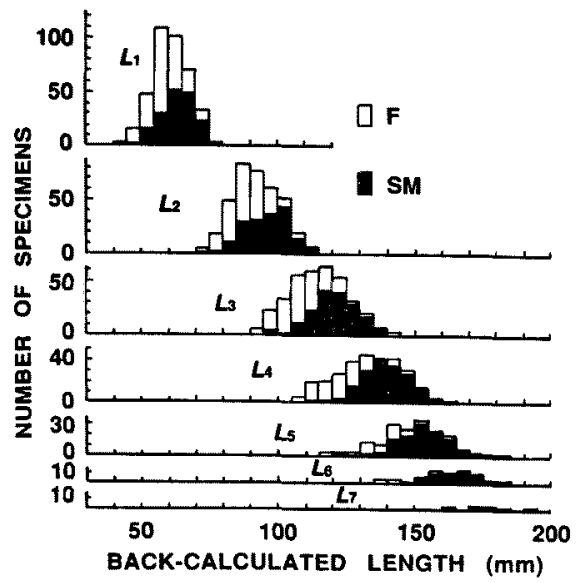

Fig. 6. Frequency distributions of the backcalculated standard length at the time of each ring formation in hermaphroditic individuals. F: data from females. SM: data from secondary males.

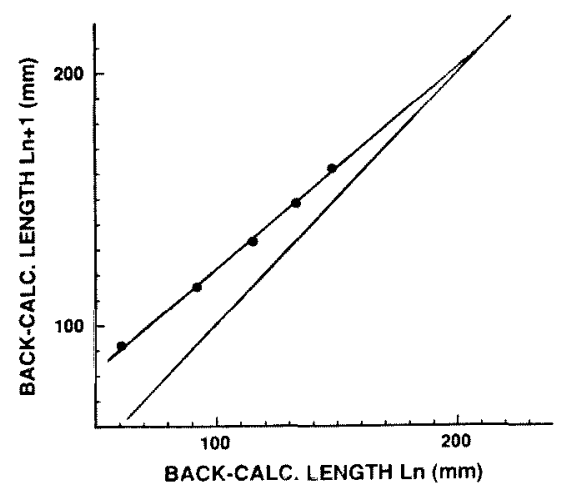

Fig. 7. Walford's growth transformation of backcalculated length.

The back-calculated length composition of hermaphroditic individuals is shown in Fig. 6. The lengths calculated from secondary males were larger than those from females. The mean values of the lengths computed from only females and those from only secondary males are also shown in Table 2. There were significant differences at the $1 \%$ level in those mean lengths between them.

\section{Growth Equations}

For growth analysis, the mean back-calculated lengths obtained from the whole materials were used because there were no significant differences

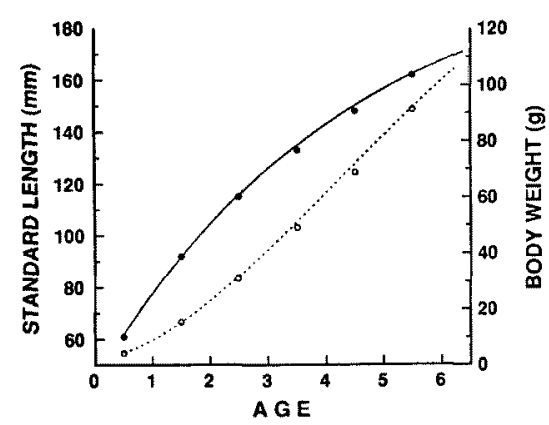

Fig. 8. Length (•) and weight $(0)$ growth curves of Halichoeres poecilopterus.

in these mean lengths between primary males and hermaphroditic individuals. The mean length at the time of the seventh ring formation was not used because the value was calculated from only 10 specimens. Walford's growth transformation $^{13)}$ of the lengths is shown in Fig. 7. The plots were almost arranged on a straight line. Therefore, the growth curve can be fitted to von Bertalanffy's model, ${ }^{14}$ ) and the equation was expressed by follows:

$$
L_{n}=211(1-\exp (-0.224(n+0.549)))
$$

Where $L_{n}=$ standard length at the time of the $n$-th ring formation.

The difference between the time of ring formation and that of hatching could be estimated to be about a half year as stated above. Thus, the relationshp between the number of ring marks $(n)$ and full age $(t)$ was expressed as the following equation:

$$
t=n-0.5
$$

Accordingly the growth curves for both length and weight represented by the full age were described as following equations (Fig. 8):

$$
\begin{aligned}
& L_{t}=211(1-\exp (-0.224(t+1.049))) \\
& W_{t}=210(1-\exp (-0.224(t+1.049)))^{3.15}
\end{aligned}
$$

where $L_{t}=$ standard length at age $t ; W_{t}=$ body weight at age $t$.

\section{Discussion}

The scales of this species were large, and the ring marks were clearly distinguishable. Thus, scale reading was rather easy although the scales taken from some older specimens had a few false rings. 
The asymptotic maximum standard length was estimated at $211 \mathrm{~mm}$; while the observed maximum lengths of the primary males and hermaphroditic individuals used here were $179 \mathrm{~mm}$ and $203 \mathrm{~mm}$, respectively. The asymptotic maximum length is rather reasonable, although slightly larger than the observed lengths.

The mean values of observed lengths of secondary males were much larger than those of females. Also the back-calculated lengths from the former were larger than those from the latter. As the cause of these phenomena, it can be considered that the larger females have a stronger tendency to change into secondary males in a certain age group, because there were no signs indicating the rapid growth such as wide distance between annual rings in secondary males at ages 4 and 5 when most of hermaphroditic individuals changed their sex, and because mane backcalculated lengths from secondary males at the time of the first to the third ring formation were larger than those from females, when most of hermaphroditicindividuals were still females.

Concerning the sex change of protogynous hermaphroditic fishes, it is well knwon that the largest female (s) in a breeding group or harem changes into the secondary male (s) after the change of their social structure such as death (or removal) of the predominant male or after the fluctuation of sex ratio in the group. ${ }^{15-18)}$ The result obtained here agrees well with this theory. Therefore, the sex change of $H$. poecilopterus also may be caused by the social control as stated above.

From the back-calculated length composition of hermaphroditic individuals, it is considered that small females in the 6-ring group hardly change into secondary males afterwards, because they are much smaller than the secondary males of 7-ring group in length. Thus, such females perhaps can not be the largest female in their breeding group and they may not change their sex throughout their life span.

Comparing the results given here with those obtained by Hashimoto et al.," the periods of the annual ring formation estimated by us and them agree well. The rings on scales were formed during the hibernation in both Ago Bay and Seto Inland sea. The materials used here show more rapid growth than those used by them. Differences in standard lengths at each age are calculated to be about 14 to $20 \mathrm{~mm}$. A difference is also shown in the length-weight relationship.
Body weight calculated by our equation is heavier than that given by their equation. These discrepancies may be caused by the difference in population density of the fish and in the fishery activity between Ago Bay and Seto Inland sea: because the fishery of the fish is much more active in Seto Inland sea than in Ago Bay, the larger individuals may be caught more often in the former than in the latter.

\section{Acknowledgments}

We would like to express our gratitude to $\mathrm{Mr}$. $T$. Kiriyama, a student of our University, for his help in collecting and measuring the specimens. Mr. Jan Dhaene, Ise City, Mie Prefecture, kindly corrected the English of the manuscript.

This work was supported partially by a Grantin-Aid for Scientific Research from the Ministry of Education, Science, and Culture.

\section{References}

1) Y. Kinoshita; On the differentiation of the male color patterns and sex ratio in Halichoeres Poecllopterus Termminck et Schlegel). J. Sci. Hiroshima Univ., Ser. B, Div. 2, Zool., 3, 65-76 (1934).

2) Y. Kinoshita: Effects of gonadectomies on the secondary sexual characters in Hallchoeres poecilopterus (Temminck et Schlegel). J. Sci. Hiroshima Univ., Ser. B, Div. 2, Zool., 4, 1-14 (1935).

3) Y. Kinoshita: Some morphological differences between sexes in Halichoeres poecilopterus (in Japanese). Plants and Animals, 3, 1275-1282 (1935).

4) Y. Kinoshita: On the accidental hermaphroditism and sexreversal in Halichoeres poecilopterus. Plants and Animals, 4, 1027-1030 (1936).

5) Y. K. Okada: Sex reversal in the Japanese wrasse, Halichoeres poecilopterus. Proc. Japan Acad., 38, 508-513 (1962).

6) Y.K. Okada: Effects on androgen and estrogen on sex reversal in the wrasse, Halichoeres poecilopterus. Proc. Japan Acad., 40, 541-544 (1964).

7) A. Nakazono: Studies on the sex reversal and spawning behavior of five species of Japanese labrid fishes. Rep. Fish. Res. Lab. Kyushu Univ., 4, 1-64 (1974).

8) Y. Fukui, K. Gushima, S. Kakuda, and H. Hashimoto: Growth-related changes in color and sex in Halichoeres poecilopterus. Japan. J. Ichthyol., 37, 395-401 (1991).

9) H. Hashimoto, K. Gushima, and S. Kakuda: On the age and growth of the labroid fish Halichoeres poecilopterus from the Seto Naikai, Japan. Nippon Suisan Gakkaishi, 57, 14571462 (1991).

10) Y. Kinoshita: On the hibernation and sleep of the labrid fishes (in Japanese). Zool. Mag., 47, 795-799 (1935).

11) R. Reinboth: Inter sexuality in fishes, in "Hormones and the Environment" (ed. by G. K. Benson and J. G. Phillips). Mem. Soc. Endocrinol., 18, 515-543 (1970).

12) S. Mio: Studies on population biology of coastal fishes in Kyushu-I: Biology of Sebastes inermis Cuvier et Valenciennes. Sci. Bull. Fac. Agr. Kyushu Unip., 18, 419-436 (1961).

13) L. A. Walford: A new graphic method of describing the growth of animals. Biol. Bull., 90, 141-147 (1946).

14) L. von Bertalanffy: A quantitative theory of organic growth. Human Biol, 10, 181-213 (1938). 
15) M. Nakamura: Histology and physiology of sex change in fishes, in "Sex Change in Fishes" (ed. by A. Nakazono and T. Kuwamura), Tokai Univ. Press, Tokyo, 1987, pp. 48-76.

16) T. Kuwamura: Social control of sex change in harems of Labroides dimidiatus, in "Sex Change in Fishes" (ed. by $A$. Nakazono and T. Kuwamura), Tokai Univ. Press, Tokyo, 1987, pp. 100-119.

17) J. T. Moyer: Social organization and protogynous her-

maphroditism in marine angelfishes (Pomacanthidac), in "Sex Change in Fishes" (ed. by A. Nakazono and T. Kuwamura), Tokai Univ. Press, Tokyo, 1987, pp. 120-147.

18) Y. Yogo: Group structure and mechanism of sex change in Anthios ssquamipinnis, in "Sex Change in Fishes" (ed. by A. Nakazono and T. Kuwamura), Tokai Univ. Press, Tokyo, 1987, pp. 148-173. 